\title{
Roles of Nanotechnological Approaches in Periodontal Disease Therapy
}

\author{
Nafiu Aminu ${ }^{1,2^{*}}$, Siok-Yee Chan ${ }^{1}$, Seok-Ming Toh ${ }^{1}$ \\ ${ }^{1}$ Discipline of Pharmaceutical Technology, School of Pharmaceutical Sciences, Universiti Sains Malaysia, 11800 USM, Penang, Malaysia. \\ ${ }^{2}$ Department of Pharmaceutics \& Pharmaceutical Microbiology, Faculty of Pharmaceutical Sciences, Usmanu Danfodiyo University, P.M.B. 2346, Sokoto, \\ Nigeria.
}

\section{ARTICLE INFO}

Article history:

Received on: 04/03/2017

Accepted on: 15/05/2017

Available online: 30/07/2017

Key words:

Nanotechnological

approaches; Nanodentistry;

Periodontal disease;

Periodontitis;

Nanoparticulate Drug

Delivery Systems.

\begin{abstract}
Formulation scientists are faced with a great hurdle of delivering a therapeutic agent into the periodontal pockets because of the anatomical complexity of the route and the lesion's contours that often leads to poor penetration of the drug to the area. However, recent nanotechnology advancement and innovations through nanodentistry are increasingly providing a suitable solution for the treatment of many dental disorders including periodontal disease. These nanodentistry innovative approaches have vowed to revolutionize dental therapeutics by way of using nanomaterials, biotechnology, and nanorobotics, that can significantly influence and transform dental disease's diagnosis, prevention, and treatment. The advances have offered possibilities for providing highquality dental care to a vast number of people around the globe who are currently suffering from periodontal disease. Novel nanotechnology-based carriers and materials such as polymeric nanoparticles, nanogels, nanopores, nanotubes, scaffold matrices, nanoneedles, nanocrystals, quantum dots, nanofibers, and nanofillers have demonstrated promising efficacy and their roles in the disease therapy are of great significance. The aim of this review article is to provide important recent updates on the various nanotechnology-base approaches for periodontal disease therapy. The roles of these recently investigated approaches in the disease treatment are also covered in the review.
\end{abstract}

\section{INTRODUCTION}

Periodontal disease is one of the major dental illnesses that affect millions of people around the globe. It is estimated that $90 \%$ of world population suffers from the disease (Pihlstrom et al., 2005). The disease is one of the major public health problem in many countries (Dias et al., 2016; Petersen and Ogawa, 2012), as it possessed the criterion such as: being widespread; having severe consequences on individuals, communities, and health services in terms of social, psychological and economic aspects (Batchelor, 2014). Periodontal disease is a chronic inflammatory disorder

\footnotetext{
* Corresponding Author

Nafiu Aminu, Discipline of Pharmaceutical Technology, School of

Pharmaceutical Sciences, Universiti Sains Malaysia, 11800 USM,

Penang, Malaysia. E-mail: nafiu.aminu@udusok.edu.ng
}

characterized by inflammation and degeneration of the teeth surrounding structures which include gums, alveolar bone, periodontal ligament (PDL) and cementum (Ali et al.,2012; Aminu et al., 2013; Chen et al., 2016; Osorio et al., 2016; Zamani et al.,2010). The disease starts with anaerobic gram-negative bacterial invasion around the gingival sulcus (Kesavalu et al., 2007), which is a region between the teeth and the gums. Then the epithelium of the gingivae migrates along the tooth surface forming periodontal pockets, which if left untreated can lead to deposition of tar and calculus by the microbes and consequently results in the destruction of the tooth neighboring structures and loss of teeth (Pihlstrom et al., 2005; Pramod et al.,2014; Tanner, 2015). Delivering drug to the gingival epithelium has been the major challenge for the formulation scientists due to the complexity of the anatomy of the route and the contours of the lesion which leads to the drug's poor penetration to the area (Schwach-Abdellaoui et al., 2000). 
There are various proposed local drug delivering devices which include films, fibers, gels and strips etc., but unfortunately, these approaches were only partially successful due to the difficulty in accessing the periodontal pockets.

However, the recent nanotechnology innovations are increasingly providing a suitable solution for the treatment of many dental disorders including periodontal disease. Nanotechnology is a discipline that has expanded rapidly into all areas of science and it offers valuable options for solving medical and scientific problems and questions (Abou Neel et al., 2015). A dental field of nanotechnology called nanodentistry is very promising and have demonstrated various treatment opportunities in dentistry in areas such as dental re-naturalization, local anesthesia, teeth hypersensitivity cure (Sahoo et al., 2007), periodontal regeneration (Walmsley et al., 2015), controlled drug delivery (Abou Neel et al., 2015; Jain et al., 2008) and overall oral health maintenance (Ozak and Ozkan, 2013), among others. This highly promising field may ensure the attainment of near perfect oral health by way of using nanomaterials, nanorobotics, biotechnology, etc. (Bhardwaj et al., 2014; Bhavikatti et al., 2014). Nanodentistry will make it possible to induce local anesthesia efficiently in the years to come, through the aid of nanorobots (Sahoo et al., 2007). Colloidal carriers containing active analgesic dental nanorobotic particles in millions and/or antibacterial agents could be directly installed into the patient's gingivae (Sahoo et al., 2007). These nanorobots would be able to make surface contact with the mucosa/crown and eventually get to dentin by moving painlessly through the gingival sulcus to the target site (Sahoo et al., 2007). The future roles of nanotechnology approaches seem to influence almost every aspect of human life, and with its advancement, researchers are acquiring abilities to understand and manipulate materials at the nanoscale (Gambhir et al., 2013).

There are various promising nanotechnology-based approaches in the field of nanodentistry that are being investigated or developed for dental therapy such as nanofibers, nanotubes, nanocapsules, nanopores, quantum dots (QDs), dendrimers, nanoshells, nanofillers, nanorods, nanorings, fullerenes, nanospheres, nanowires and nanobelts (Chen et al., 2016; Kong et al., 2006; Zupančič et al.,2015a). Some of these approaches have demonstrated satisfactory outcomes toward minimizing undesirable side-effects for various active agents while maximizing the therapeutic activity.

Many authors reported review articles about local drug delivery systems for the treatment of periodontal disease (Hau et al., 2014; Pragati et al., 2009; Puri and Puri, 2013; SchwachAbdellaoui et al., 2000), and few reviews have also discussed some applications of nanotechnology-based delivery systems in the treatment of the disease (Goyal et al., 2014; Zupancic et al.,2015b). However, review articles that provide detail account on specific roles of various nanotechnology-based approaches for periodontal disease therapy are lacking. In order to bridges the gap, this review covers various recently investigated nanotechnology-based approaches for the treatment of periodontal disease, with emphasis on the keys roles which these approaches play towards achieving effective therapy.

\section{ROLES OF NANOTECHNOLOGY-BASED APPROACHES In nanodiagnostics}

Over the years, many strategies have been designed and implemented for the diagnosis of dental illnesses including periodontal disease. However, most of them suffer accessibility problem, hence the need for concerted efforts to improve diagnostic tools and techniques. Nanotechnological innovations provide scientists and researchers with the new hope for progress in this direction through the advent of nanodiagnostics and its rapid transformation. Nanodiagnostics is a phenomenon that involves the use of nanotechnological advancement for clinical and molecular diagnostic purposes (Azzazy et al., 2006; Jain, 2005). The increased demands for highly sensitive and early disease detection tools has led to the development of this novel technology, in order to meet the demands of clinical diagnostics (Azzazy et al., 2006; Jain, 2005). Nanodiagnostics would significantly reduce the waiting time for results after a test is conducted. The technology will help in the use of nanodevices for early disease diagnosis at molecular and cellular level. The possibility of using nanosized QDs technology based on immune fluorescence has provided researchers an opportunity to be able to precisely label specific periodontal pathogenic bacteria, which therefore enable its identification and removal (Alharbi and Alsheikh, 2014; Azzazy et al., 2006).

The technique could be employed for single cell resolution for both in vivo and in vitro labeling of microbes. Therefore, since specific pathogenic microorganisms have been associated with the development of periodontal disease, the nanomaterial technological potentials such as those exhibited by QDs, may enable a clear diagnosis of the disease (Bhavikatti et al., 2014; Chalmers et al., 2007).

\section{Quantum dots (QDs)}

QDs are among the most promising nanostructures for diagnostic applications. These are new material that promise fundamental transformation in medical labeling techniques. QDs are tiny semiconductor nanocrystals that are stable, non-toxic and glow brightly when stimulated by ultraviolet light. Their strong light absorbance property qualifies them to be used as fluorescent labels for biomolecules (Alharbi and Al-sheikh, 2014).

Their roles are beyond diagnostic applications, as they have also been found to play the role of photosensitizer and carrier (Bhardwaj et al., 2014). QDs can attach an antibody to the target cell upon stimulation by UV light, and consequently yield a reactive oxygen species that is capable of destroying the target cells (Bhardwaj et al., 2014). Some other roles of QDs are their ability to be embedded into dental resins to tune the emission color of the resin. Lead-free and cadmium-free QDs are employed in periodontal therapy to enhance the healing of inflamed periodontal tissues (Harini and Kaarthikeyan, 2014). 


\section{Nanoscale cantilevers}

Nanoscale cantilevers are tiny beams resembling a row of diving boards or those as in atomic force microscopy, and they are fabricated by using semiconductor lithographic techniques (Azzazy et al., 2006). Nanoscale cantilevers exercise its function through nanomechanical deflections and are used for deoxyribonucleic acid (DNA) hybridization to monitor molecular events (Azzazy et al., 2006). When nanoscale cantilevers are coated with certain receptor molecules, they can bind to specific DNA-substrates; bacterial cells; or viruses, and the overall effect would be the detection of single molecules (DNA or protein); specific pathogenic bacteria or viruses (Jain, 2003; Jain, 2005; Saxl, 2011; U.S. National Cancer Institute, 2016). Nanoscale cantilevers are developed as an integral division of larger diagnostic tools that can provide sensitive and rapid detection of inflammation and cancer-associated molecules, of which periodontal disease could be an important target. Through the cantilevers, it is possible to detect disease such as periodontitis and to comprehend the mechanism of the disease and its potential cure (Saxl, 2011). Nanoscale cantilevers can scan sample and yield hybridization with the single-stranded DNA when the targeted sequence is determined. This is another important feature of cantilevers that can permit multiple analyses (Fortina et al., 2005; Jain, 2003).

\section{Gold nanoparticles}

Gold nanoparticles are among the novel diagnostic tools for healthcare investigations. They are developed from thin gold layers or tiny gold spheres and possess good detection sensitivity for various targets (West and Halas, 2003). Gold nanoparticles that are coated with silver shells possess strong light-scattering properties with improved detection capacity (Cao et al., 2002; West and Halas, 2003). These essential diagnostic materials can allow rapid, direct and economically feasible analysis of samples from whole blood. They have several physical properties that make them suitable for medical applications. The applications of gold nanoparticles stretch from diagnosis to drug delivery for therapy of diseases (Mieszawska et al., 2013). Gold nanoparticles can be functionalized to detect specific targets due to their high surface-to-volume ratios which offer higher selectivity as compared to conventional approaches (Mieszawska et al., 2013; Vinhas et al., 2015). Early diagnosis of periodontal disease is essential in order to initiate suitable therapy and prevent its progression to advance form of the disease. The unique essential optical features of gold nanoparticles, as described above make them a key role players in the early and rapid diagnosis of periodontal disease.

\section{Nanotubes}

Nanotubes such as boron nitride or carbon rods are very small and are used as electrodes with single-stranded DNA probes for detection sensitivity in the attomole range, and in hybridization of the target DNA or protein. They can also be adapted for analytes other than DNA, e.g., by attaching enzyme to detect substrate analyte (Azzazy et al., 2006; Fortina et al., 2005). Nanotubes offer interesting advantages that are relative to or better than spherical nanoparticles in some biotechnological and diagnostic applications (Kong et al., 2006). Its internal and external surfaces can be chemically functionalized to entrap drugs, and their unique open-ended barrels may make the internal surface accessible and allow incorporation of certain active molecules within the tubes easily (Kong et al., 2006).

Therefore, the inner volumes of the tubes can be filled with any suitable chemical or biochemical agent for delivery to the targeted location. Examples of nanotubes include fullerene carbon nanotubes, organosilicon polymer nanotubes, peptide nanotubes and template-synthesized nanotubes (Kohli and Martin, 2003; Kong et al., 2006).

\section{Nanopores}

These are tiny (molecular-scale) structures that have great sensitivity and detection capability of the conformation and location of a single molecule that is situated in the pore lumen (Bayley and Jayasinghe, 2004; Wang et al., 2011). The nanoholes of nanopores can permit passage of DNA and can also make DNA sequencing even more efficient. The characteristic change in the nanopores conductance enables researchers to be able to electrically elucidate single-molecule kinetic pathways as well as quantify the target easily (Wang et al., 2011). Significant progress has been made in material science and nanotechnology towards designing intelligently gated nanoporous devices (Harini and Kaarthikeyan, 2014).

Through nanopore technological innovations, it became possible to count and/or distinguish between a variety of unlike molecules in a complex mixture (Jain, 2005). For instance, the technology can allow the differentiation between hybridized or unhybridized unknown DNA and RNA molecules that differ only by a single nucleotide (Jain, 2005). This technology could be applied in periodontal disease diagnosis at the molecular level.

\section{In prevention}

For a very long time, conventional dentifrices such as gargles, mouthwashes, toothpaste and throat paints have been the most commonly used traditional products for maintaining oral hygiene and oral preventive measures, until recently when nanotechnology provide novel approaches for preventive measures against oral cavity diseases such as periodontal disease and dental caries (Abou Neel et al., 2015). Certain agents in nanoscale can be incorporated in these conventional dentifrices to aid in repelling the deposition of bacterial biofilms (plaque and tar) and/or prevent dental caries by remineralization of early carious lesions, and in desensitization of abraded teeth (Hannig and Hannig, 2010). The process of re-deposition of minerals that are lost by tooth enamel is called enamel remineralization (Cury and Tenuta, 2009). Some ceramics like calcium phosphates and nanosized calcium carbonate particles (also called hydroxyapatite) has been reported to be a suitable ingredient for dentifrices that can be effectively used in the process of enamel remineralization. Among these ceramics, 
hydroxyapatite gain more attention being it the prototype in bone as well as tooth apatite crystals, and also one of the main constituents of natural bone. Therefore, its applications as bone implant are being extensively investigated in a different variety of forms (Vandiver et al., 2005). Study conducted by Nakashima et al. (2009) showed that there is $48.8 \%$ improvement on the remineralization of artificially produced subsurface enamel lesions when the nanosized calcium carbonate particles were incorporated in dentifrices. Furthermore, nanocarbonate apatite has proven to be very efficacious desensitizing dentifrice when compared with the conventional agents (Lee et al., 2008).

Mouthwashes containing silver nanoparticles and triclosan-loaded nanoparticles have exhibited plaque control actions which are vital for the prevention of periodontal disease. Silver nanoparticles demonstrated strong antibacterial effects in dental products, because of the antibacterial properties of silver (Allaker, 2010; Besinis et al.,2014). Studies showed that nanoparticles of silver imparted high antibacterial activity on dental resins, which significantly reduces building-up of biofilm as well as lactic acid production by the oral bacteria without interfering with the resins' mechanical and physical properties (Cheng et al., 2015). In one investigation, carbonate hydroxyl apatite nanoparticles have been found to be highly effective in repairing some tooth defects (micrometer-sized) in vitro (Cheng et al., 2015), and some of its nanocrystals were incorporated in dentifrices like mouthwash solutions and toothpaste and used as commercial products (Lei et al., 2016; Nakashima et al., 2009).

A team of researchers have investigated the anti-adhesive effect of low surface free energy nanocomposite coating materials against bacterial biofilm accumulation around the tooth surface, in order to prevent pathogenic consequences of intra-pocket biofilm build-up and also to hinder bacterial attachment on the tooth (Hannig et al., 2007). They applied an inorganic nanocomposite coating (with a surface free energy of $18-20 \mathrm{~mJ} / \mathrm{m} 2$ ) to enamel and titanium specimens. The specimens were analyzed by transmission electron microscopy after intraoral exposure. The results showed that specimens that were coated with the nanocomposite significantly reduced biofilm formation and accumulation. Moreover, easy-to-clean surface characteristics were achieved by coating enamel as well as titanium with the nanocomposite which resulted in faster removal of the biofilms under oral conditions (Hannig et al., 2007). Possible applications of the nanocomposite could be tooth coatings after restorations, sealants agent and coating of transmucosal parts of implants or dentures (Hannig et al., 2007; Hannig and Hannig, 2010).

Other preventive nanotechnology-based approach for periodontal disease is fabrication of products for oral health care that are integrated with bioinspired apatite nanoparticles alone or together with proteinaceous substances (like casein phosphopeptides) (Rahiotis et al., 2008). Casein phosphopeptide demonstrated an important role in biomimetic strategies for overall bacterial biofilm management. In vivo studies showed evidence which indicated that casein phosphopeptide coupled with amorphous calcium phosphate nanocomplexes reduces bacterial adherence on the tooth surface (Figure 1), by adsorbing the bacterial macromolecules, as well as binding to the surfaces of bacterial cells and to the components of the intercellular plaque matrix (Cross et al., 2007). Similarly, in vitro experiments demonstrated that clustered and non-aggregated hydroxyl apatite nanocrystallite particles can bind on the bacterial surface, and then interact with its adhesins in order to disrupt the attachment of the microbes on the tooth surface (Hannig and Hannig, 2010).

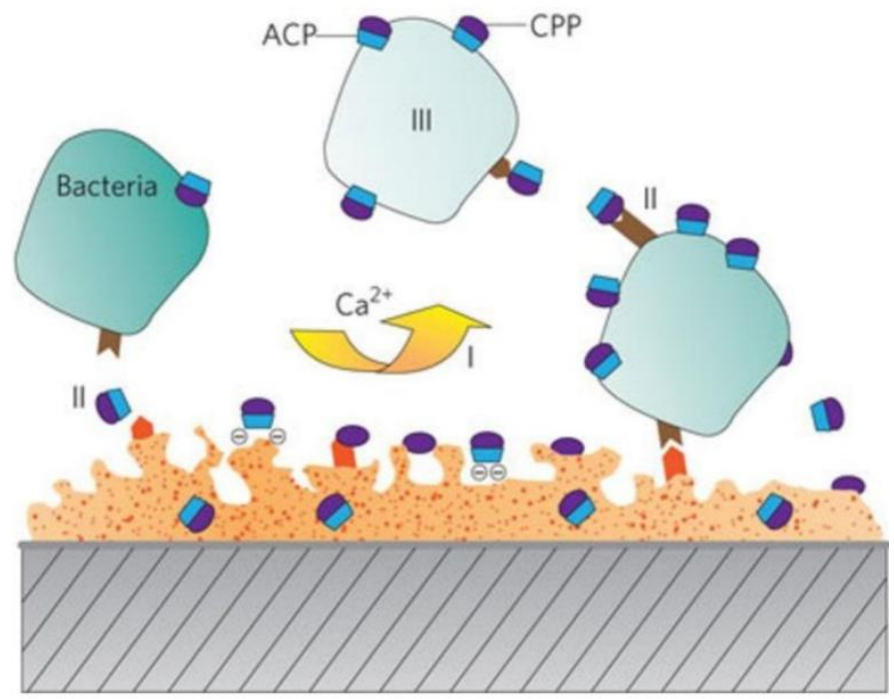

Fig. 1: Diagrammatical demonstration of how ACP-CPP prevent the oral biofilm formation by hindering bacterial adhesion. CPP block the adhesion by binding to the pellicle. It competes with calcium for plaque-calcium binding sites (I) and reduces the quantity of calcium that connects the bacteria with the pellicle, and between the bacterial cells. This will result in blocking specific receptor molecules (red) in the pellicle layer as well as on the bacterial surfaces (brown), which further decreases the adhesion and co-adhesion (II), and will interfere with the viability of the bacteria (III).

ACP, amorphous calcium phosphate; CPP, casein phosphopeptide

The figure was adapted with permission from Macmillan Publishers Ltd: Nature Nanotechnology, (Hannig and Hannig, 2010), copyright 2017.

\section{In dental restorative}

One of the major consequences of periodontal disease is a progressive loss of teeth supporting structures viz. gums, alveolar bone, cementum and periodontal ligament, that occurs as a result of the destructive effect of pathogenic bacteria which invade the periodontium (Simch et al., 2008). Ultimately, partial or complete loss of tooth structures will be the clinical endpoint (Chen et al., 2016). To manage this, a dental restorative procedure should be performed to restore the morphology, integrity, and function of the missing structures.

There is an urgent need for the development of improved synthetic materials such as orthopedic implants, that can be used in the event of severe bone damage or lost caused by diseases such as severe periodontitis and osteoporosis (Vandiver et al., 2005).

Nanotechnology has been recently employed in dental restorative techniques through the use of nanomaterials like nanofillers for what is called "white fillings" (Bhavikatti et al., 
2014; Lorden et al.,2015). This involved the incorporation of nanofiller particles in composite resins, which eventually yield a new class of restorative materials with improved properties than that of the conventional microfilled and macrofilled composites. Advancement in filler technology can be utilized in the development of novel resin-based dental restoratives with enhanced mechanical properties (Bhavikatti et al., 2014). The recent remarkable evolution in nanotechnology-based restorative dentistry has resulted in restorative materials with superior properties which have also significantly improved dental therapy. In particular, the technology has been successfully applied for the manufacture of endodontic sealers, dental nanocomposites, nano-ionomerscement, and also in tooth regeneration as well as aesthetics purposes (Khurshid et al., 2015; Melo et al., 2013).

\section{Nanofillers}

Nanofillers are gaining considerable attention as vital dental nanomaterials for incorporation into commercial composite materials for different dental applications. There are various methods employed for the synthesis of nanofillers such as sol-gel processes, flame pyrolysis and flame spray pyrolysis (Khurshid et al., 2015). The dimensions of nanofiller particles are less than that of visible light. Therefore, neither can they be absorbed no do they scatter visible light, and this feature plays an important role for their aesthetic features and hence, they can be employed for anterior teeth restorations (Khurshid et al., 2015). Nanofillers act by enhancing the union between the macroscopic natural tooth structural surfaces with its nanosized filler particles, which can result in a strong natural and advanced boundary (Ozak and Ozkan, 2013).

It also has the potential to create micromechanical fillerresin matrix interphase bonding. To establish and validate this property, Samuel et al. (2009) investigated the use of mesoporous fillers in dental composites. They prepared experimental dental composites by blending mesoporous silica and nonporous spherical silica together and then evaluated the compressive modulus, compressive strength, flexural modulus and flexural strength of these composites. The results showed that the composites made by nonporous and mesoporous filler combinations possessed improved mechanical properties as compared to the composites with either of these fillers alone. This finding means that combinations of nonporous and mesoporous materials could be used to develop better dental materials that can withstand hydrolysis and wear.

\section{Dental nanocomposites}

Because of the excellent properties of dental nanocomposites such as good translucency and contouring, it has been used for restoring the damaged or lost dental tissues, as indicated in Figure 2 (Khurshid et al., 2015). In order to improve mechanical properties as well as enhanced polymerization kinetics of dental resin, attachment of monovinyl methacrylate monomers was made on the resin, and this addition has expanded its applications in dental therapy (Cramer et al.,2011; Khurshid et al., 2015).

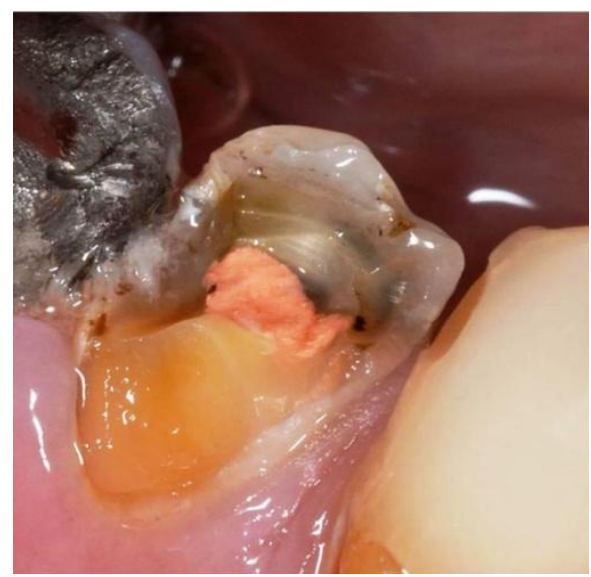

A

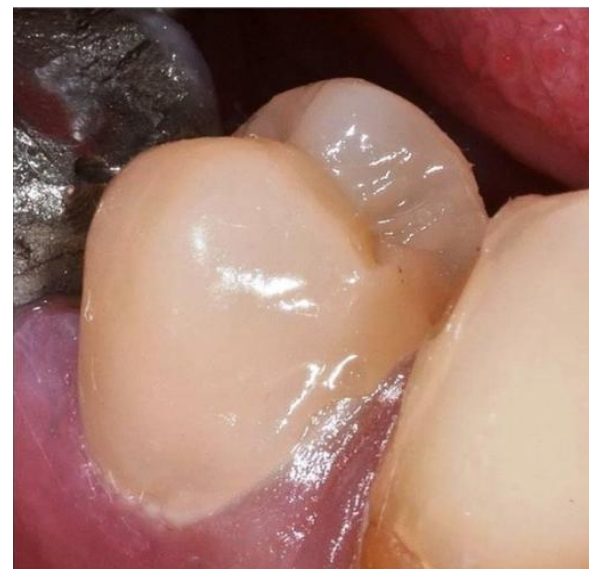

B

Fig. 2: Nanocomposite restorative materials were used in filling and restoration of teeth. (a) Non-restored premolar tooth and treated root; (b) Modern nanocomposite restorative materials were used to build up the tooth completely (Khurshid et al., 2015).

\section{Bone grafting}

Dental bone grafting is a procedure for recovering tooth bone that was lost following severe periodontal disease, and it involves recreation of the lost bone. Bone grafting may also be used to maintain bone structure after tooth extraction. Bone grafting is faced with limitations such as a limited supply of grafting materials, variable resorption, high failure rates and persistent pains (Walmsley et al., 2015). These limitations have evoked massive research for solutions to these limitations. 3D scaffold matrices and nano-engineered particles that promote the growth of new bone have been the main areas of focus (Lorden et al., 2015; Walmsley et al., 2015), and scaffold have been successfully used in various fields of tissue engineering such as periodontal regeneration and bone formation (Garg et al., 2012).

Various alloplastic bone grafts with nanoscale particle sizes are being developed and tested. One of the recent and most promising among them are nano-hydroxyapatite (n-HAP) bone grafts, which is available in crystalline, chitosan-associated and titanium-reinforced forms (Kailasanathan et al., 2012). When 
compared with the 'plain' chitosan scaffolds, 'n-HAP' composite bone graft scaffolds demonstrated greater biocompatibility, superior mechanical properties and also appeared to induce better cellular responses (Chesnutt et al., 2009). In another development, n-HAP and nanosized crystals of calcium sulphate have been synthesized and evaluated on intrabony defects. Both the nanocrystalline materials demonstrated clinically significant treatment outcomes in terms of bone regeneration and resistance to degradation than their conventional counterparts (Kathuria et al., 2012). Similarly, a nanoceramic composite material with antibacterial effect has been developed, by encapsulation/ entrapment of zinc oxide nanoparticles, nanocalcium phosphate and walled carbon nanotubes in alginate polymer matrix. The nanoceramic composite show promising result for bone grafting, that includes regeneration of bone caused by intrabony defects and enhancement of hydroxyapatite formation in bone defects (Beherei et al., 2011). In another similar investigation, a precursor of hydroxyapatite called octacalcium phosphate has been synthesized and it has demonstrated a great role in apatite crystal development. The investigation provided evidence that this octacalcium phosphate stimulates bone formation which is even more than that stimulated by synthetic hydroxyapatite in bone defects. Although the precise mechanism of action has not been fully elucidated, but it is likely that the octacalcium phosphate precursor plays a role in bone forming cells stimulation through interaction with the closely encircling tissue (Suzuki, 2010).

\section{In drug delivery}

An ideal drug delivery system should be able to transport active compound(s) to the intended site of action safely. In the present context however, ideal drug delivery should be able to make optimum contact with the mucosal surfaces in the periodontium and should prolong the residence time at the targeted site (i.e. in the periodontal pocket), and should also intensify contact with the junctional epithelium so as to enhance the epithelial transport of poorly absorbable drugs. This is a desirable approach in order to improve the regeneration ability of damaged tissues and to effectively treat periodontal disease (Abou Neel et $a l ., 2015)$. Nanotechnological drug delivery approaches are highly promising in achieving these goals. It provides an avenue by which therapeutic molecules could been capsulated/loaded in carriers, such as nanoparticles or scaffolds, to allow targeted, sustained and controlled release to the intended location (Abou Neel et al., 2015). Nanoparticulate drug delivery systems are among the most popular fields of current research for periodontal treatment and regeneration. A significant number of nanoparticulate drug delivery systems have been developed during the last two decades and many of them have yielded promising results (Chen et al., 2016). Better penetration of the active moiety into the junctional epithelium (site of action) combined with optimal drug release profiles are among the important benefits of this approach. Drug concentration in the periodontal tissue can be improved by incorporating the drug into controlled release delivery systems that can be placed locally in the periodontal pockets (Piñón-Segundo et al., 2005; Schwach-Abdellaoui et al., 2000). The local delivery of antimicrobial agents to the periodontal pockets has the benefit of the drug reaching the target site at low dose thus minimizing exposure of the drug in the entire body (Hau et al., 2014; Pragati et al., 2009). Local delivery systems with sustain release effect might also be applicable for areas with accessibility difficulties due to anatomical complexity or depth, as in furcation defects (Kornman, 1993). Several studies have shown that an effective approach to optimize the targeting or to enhance the action of drugs is to associate the active moiety with a carrier system (Pramod et al., 2014). Some of the secarrier systems and their roles in periodontal disease therapy are summarized in Table 1.

Table 1: Various investigated nanoparticulate drug delivery systems and their roles in periodontal disease therapy.

\begin{tabular}{|c|c|c|}
\hline Delivery system & Role(s) & References \\
\hline \multirow[t]{4}{*}{ Nanoparticles } & $\begin{array}{l}\text { Potential carrier system } \\
\text { for the delivery of active } \\
\text { substances to the } \\
\text { periodontal pocket }\end{array}$ & (Aminu et al., 2013) \\
\hline & $\begin{array}{l}\text { Triclosan-nanoparticles } \\
\text { could help decrease } \\
\text { gingival inflammation }\end{array}$ & $\begin{array}{c}\text { (Piñón-Segundo et al., } \\
\text { 2005) }\end{array}$ \\
\hline & $\begin{array}{l}\text { Minocycline-loaded } \\
\text { nanoparticles could } \\
\text { significantly decrease } \\
\text { symptoms of } \\
\text { periodontitis } \\
\end{array}$ & (Yao et al., 2014) \\
\hline & $\begin{array}{l}\text { Calcium and zinc- } \\
\text { loaded bioactive and } \\
\text { cytocompatible } \\
\text { nanoparticles represent } \\
\text { a promising tool for } \\
\text { therapeutic approach in } \\
\text { periodontal regeneration }\end{array}$ & (Osorio et al., 2016) \\
\hline \multirow[t]{2}{*}{ Nanogels } & $\begin{array}{l}\text { Nanogels of cholesterol- } \\
\text { bearing pullulan } \\
\text { modified with amino } \\
\text { groups }\left(\mathrm{CHPNH}_{2}\right) \text { were } \\
\text { utilized as a career to } \\
\text { introduce QDs into PDL } \\
\text { cells }\end{array}$ & (Fukui et al., 2007) \\
\hline & $\begin{array}{l}\mathrm{CHPNH}_{2}-\mathrm{QD} \\
\text { nanoparticles are useful } \\
\text { for further } \\
\text { characterization of PDL } \\
\text { cells and investigation } \\
\text { of regenerative } \\
\text { processes of } \\
\text { periodontium }\end{array}$ & (Fukui et al., 2007) \\
\hline \multirow[t]{2}{*}{ Nanocomposites } & $\begin{array}{l}\text { Thin layer of } \\
\text { nanocomposites has } \\
\text { been used to provide } \\
\text { coating on tooth surface, } \\
\text { which strongly reduced } \\
\text { biofilm formation }\end{array}$ & (Hannig et al., 2007) \\
\hline & $\begin{array}{l}\text { Nanocomposite } \\
\text { hydrogels were } \\
\text { synthesized as model } \\
\text { systems and it offers } \\
\text { flexibility for local } \\
\text { placement of drugs in } \\
\text { the treatment of } \\
\text { periodontal disease }\end{array}$ & (Bako et al., 2008) \\
\hline
\end{tabular}




\begin{tabular}{|c|c|c|}
\hline & $\begin{array}{l}\text { Dental bioactive } \\
\text { nanocomposite } \\
\text { composed of 2- } \\
\text { methacryloyloxyethyl } \\
\text { phosphoryl choline and } \\
\text { dimethylamino } \\
\text { hexadecyl methacrylate } \\
\text { is promising for Class V } \\
\text { restorations to inhibit } \\
\text { periodontal pathogens, } \\
\text { combat periodontitis } \\
\text { and protect the } \\
\text { periodontium }\end{array}$ & (Wang et al., 2016) \\
\hline \multirow[t]{5}{*}{ Nanofibers } & $\begin{array}{l}\text { Poly- } \varepsilon \text {-caprolactone } \\
\text { (PCL) nanofibers } \\
\text { containing } \\
\text { metronidazole showed } \\
\text { prolonged sustained } \\
\text { drug release for at least } \\
19 \text { days and can be used } \\
\text { as a retentive, locally } \\
\text { controlled delivery } \\
\text { system for } \\
\text { metronidazole in } \\
\text { periodontal diseases } \\
\text { treatment }\end{array}$ & $\begin{array}{l}\text { (Chaturvedi } \text { et al., 2012; } \\
\text { Zamani } \text { et al., 2010) }\end{array}$ \\
\hline & $\begin{array}{l}\text { Low-dose controlled- } \\
\text { release PCL nanofibers } \\
\text { containing doxycycline } \\
\text { showed sustained drug } \\
\text { release and can be used } \\
\text { as a retentive controlled } \\
\text { delivery system for the } \\
\text { treatment of periodontal } \\
\text { diseases }\end{array}$ & (Chaturvedi et al., 2013) \\
\hline & $\begin{array}{l}\text { Drug loaded hyaluronic } \\
\text { acid-polyvinyl alcohol } \\
\text { nanofiber patch } \\
\text { presented controlled } \\
\text { release behavior with } \\
\text { good mucoadhesive } \\
\text { strength }\end{array}$ & (Joshi et al., 2015) \\
\hline & $\begin{array}{l}\text { The in vivo studies } \\
\text { confirmed the } \\
\text { maintenance of } \\
\text { minimum inhibitory } \\
\text { concentration over an } \\
\text { extended period in } \\
\text { addition to a significant } \\
\text { anti-inflammatory } \\
\text { effect, which suggested } \\
\text { the formulation's role as } \\
\text { an intra-periodontal } \\
\text { pocket drug delivery } \\
\text { system }\end{array}$ & (Joshi et al., 2015) \\
\hline & $\begin{array}{l}\text { Resveratrol-loaded PCL } \\
\text { nanofibers improved } \\
\text { low solubility and } \\
\text { stability of resveratrol } \\
\text { and it can supply the } \\
\text { drug for treatment of } \\
\text { periodontal disease in } \\
\text { the periodontal pocket } \\
\text { even longer due to } \\
\text { sustained release and } \\
\text { low gingival fluid flow }\end{array}$ & (Zupančič et al., 2015a) \\
\hline
\end{tabular}

\section{CONCLUSION}

The advancement of nanotechnology in dental science has brought tremendous progress in periodontal disease therapy.
The technology offers significant promise in the disease's early diagnosis even at molecular and cellular level, thereby reduces the waiting time for results. It also play an important roles in the prevention of the disease, through using nanoscale agents to repel bacterial biofilms deposition and accumulation on the tooth surface, and by remineralization and desensitization of abraded teeth. Nanodentistry have also make the development of potent restorative nanomaterials possible. Such materials can promote the growth of new bone structure in intrabony defect and can also be used for tooth regeneration and for aesthetics purposes. Moreover, there have been significant progress in periodontal drug delivery systems through the recent nanotechnological advancement, whereby therapeutic agents could be loaded in carriers that can facilitate targeted, sustained and controlled release of the loaded $\operatorname{drug}(s)$ to the intended location. Certainly, nanotechnology-based drug carrier systems will play a vital role in future drug delivery systems for not only periodontal disease, but for a lot of other oral cavity diseases. Investigations are underway for more exploitation of the effectiveness and significance of these vital therapeutic drug carrier systems. These advances may simplify periodontal disease treatment and may help bring dental care closer to millions of people around the globe that doesn't have access to high-quality oral healthcare.

\section{ACKNOWLEDGEMENT}

Financial support and sponsorship: Mr. Nafiu Aminu wish to gratefully acknowledge the support provided by Universiti Sains Malaysia (USM), Penang through the USM fellowship.

Conflict of Interests: There are no conflicts of interest.

\section{REFERENCES}

Abou Neel EA, Bozec L, Perez RA, Kim H-W, Knowles JC. Nanotechnology in dentistry: prevention, diagnosis, and therapy. Int $\mathrm{J}$ Nanomedicine, 2015;10:6371-6394.

Alharbi KK, Al-sheikh YA. Role and implications of nanodiagnostics in the changing trends of clinical diagnosis. Saudi J Biol Sci, 2014;21:109-117.

Ali MS, Ali J, Ahuja A, Alam MS. Formulation and Characterization of Dental Film Containing Ofloxacin. J App Pharm Sci, 2012;2:114-119.

Allaker RP. The Use of Nanoparticles to Control Oral Biofilm Formation. J Dent Res, 2010;89:1175-1186.

Aminu N, Baboota S, Pramod K, Singh M, Dang S, Ansari SH, et al. Development and evaluation of triclosan loaded poly- $\varepsilon$-caprolactone nanoparticulate system for the treatment of periodontal infections. J Nanoparticle Res, 2013;15:2075.

Azzazy HME, Mansour MMH, Kazmierczak SC. Nanodiagnostics: A new frontier for clinical laboratory medicine. Clin Chem, 2006;52:1238-1246.

Bako J, Szepesi M, Veres AJ, Cserhati C, Borbely ZM, Hegedus C, et al. Synthesis of biocompatible nanocomposite hydrogels as a local drug delivery system. Colloid Polym Sci, 2008;286:357-363.

Batchelor P. Is periodontal disease a public health problem? Br Dent J, 2014;217:405-409.

Bayley H, Jayasinghe L. Functional engineered channels and pores (Review). Mol Membr Biol, 2004;21:209-220. 
Beherei HH, El-Magharby A, Abdel-Aal MS. Preparation and characterization of novel antibacterial nano- ceramic-composites for bone grafting. Der Pharma Chem, 2011;3:10-27.

Besinis A, De Peralta T, Handy RD. Inhibition of biofilm formation and antibacterial properties of a silver nano-coating on human dentine. Nanotoxicology, 2014;8:745-754.

Bhardwaj A, Bhardwaj A, Misuriya A, Maroli S, Manjula S, Singh AK. Nanotechnology in dentistry: Present and future. J Int Oral Heal, 2014;6:121-126.

Bhavikatti SK, Bhardwaj S, Prabhuji ML V. Current applications of nanotechnology in dentistry: a review. Gen Dent, 2014;62:72-77.

Cao YC, Jin R, Mirkin C. Nanoparticles with Raman Spectroscopic Fingerprints for DNA and RNA Detection. Science, 2002;297:1536-1540.

Chalmers NI, Palmer RJ, Du-Thumm L, Sullivan R, Shi W, Kolenbrander PE. Use of Quantum Dot Luminescent Probes To Achieve Single-Cell Resolution of Human Oral Bacteria in Biofilms. Appl Environ Microbiol, 2007;73:630-636.

Chaturvedi TP, Srivastava R, Srivastava AK, Gupta V, Verma PK. Doxycycline Poly E-Caprolactone Nanofibers in Patients with Chronic Periodontitis - A Clinical Evaluation. J Clin Diagnostic Res, 2013;7:2339-2342.

Chaturvedi TP, Srivastava R, Srivastava AK, Gupta V, Verma PK. Evaluation of metronidazole nanofibers in patients with chronic periodontitis: A clinical study. Int J Pharm Investig, 2012;2:213-217.

Chen X, Wu G, Feng Z, Dong Y, Zhou W, Li B, et al. Advanced biomaterials and their potential applications in the treatment of periodontal disease. Crit Rev Biotechnol, 2016;36:760-775.

Cheng L, Zhang K, Weir MD, Melo MAS, Zhou X, Xu HH. Nanotechnology strategies for antibacterial and remineralizing composites and adhesives to tackle dental caries. Nanomedicine, 2015;10:627-641.

Chesnutt BM, Viano AM, Yuan Y, Yang Y, Guda T, Appleford $\mathrm{MR}$, et al. Design and characterization of a novel chitosan/nanocrystalline calcium phosphate composite scaffold for bone regeneration. J Biomed Mater Res Part A, 2009;88:491-502.

Cramer NB, Stansbury JW, Bowman CN. Recent Advances and Developments in Composite Dental Restorative Materials. J Dent Res, 2011;90:402-416.

Cross KJ, Huq NL, Reynolds EC. Casein phosphopeptides in oral health--chemistry and clinical applications. Curr Pharm Des, 2007; 13:793-800.

Cury JA, Tenuta LMA. Enamel remineralization: controlling the caries disease or treating early caries lesions? Braz Oral Res, 2009;23:23-30.

Dias RJ, Havaldar VD, Ghorpade VS, Mali KK, Gaikwad VK, Kumbhar DM. Development and Evaluation of In-Situ Gel Containing Ornidazole Loaded Microspheres for Treatment of Periodontitis. J App Pharm Sci, 2016;6:200-209.

Fortina P, Kricka LJ, Surrey S, Grodzinski P. Nanobiotechnology: the promise and reality of new approaches to molecular recognition. Trends Biotechnol, 2005;23:168-173.

Fukui T, Kobayashi H, Hasegawa U, Nagasawa T, Akiyoshi K, Ishikawa I. Intracellular delivery of nanogel-quantum dot hybrid nanoparticles into human periodontal ligament cells. Drug Metab Lett, 2007;1:131-135

Gambhir RS, Sogi G, Nirola A, Brar R, Sekhon T, Kakar H. Nanotechnology in dentistry: Current achievements and prospects. J Orofac Sci, 2013;5:9-14.

Garg T, Singh O, Arora S, Murthy RSR. Scaffold: A Novel Carrier for Cell and Drug Delivery. Crit Rev Ther Drug Carrier Syst, 2012;29:1-63.

Goyal G, Garg T, Rath G, Goyal AK. Current nanotechnological strategies for an effective delivery of drugs in treatment of periodontal disease. Crit Rev Ther Drug Carrier Syst, 2014;31:89-119.

Hannig M, Hannig C. Nanomaterials in preventive dentistry. Nat Nanotechnol, 2010;5:565-569.
Hannig M, Kriener L, Hoth-Hannig W, Becker-Willinger C, Schmidt $\mathrm{H}$. Influence of nanocomposite surface coating on biofilm formation in situ. J Nanosci Nanotechnol, 2007;7:4642-4648.

Harini G, Kaarthikeyan G. Advanced Drug Delivery Systems in Treating Periodontal Diseases-A Review. IOSR J Dent Med Sci, 2014;13:27-32.

Hau H, Rohanizadeh R, Ghadiri M, Chrzanowski W. A minireview on novel intraperiodontal pocket drug delivery materials for the treatment of periodontal diseases. Drug Deliv Transl Res, 2014;4:295301.

Jain K. Nanodiagnostics: application of nanotechnology in molecular diagnostics. Expert Rev Mol Diagn, 2003;3:153-161.

Jain KK. Nanotechnology in clinical laboratory diagnostics. Clin Chim Acta, 2005;358:37-54

Jain N, Jain GK, Javed S, Iqbal Z, Talegaonkar S, Ahmad FJ, et al. Recent approaches for the treatment of periodontitis. Drug Discov Today, 2008;13:932-943.

Joshi D, Garg T, Goyal A, Rath G. Development and Characterization of Novel Medicated Nanofibers Against Periodontitis Curr Drug Deliv, 2015;12:564-577.

Kailasanathan C, Selvakumar N, Naidu V. Structure and properties of titania reinforced nano-hydroxyapatite/gelatin biocomposites for bone graft materials. Ceram Int, 2012;38:571-579.

Kathuria R, Pandit N, Jain A, Bali D, Gupta S. Comparative Evaluation Of Two Forms Of Calcium Sulfate Hemihydrate For The Treatment Of Infrabony Defects. Indian J Dent Sci, 2012;4:30-36.

Kesavalu L, Sathishkumar S, Bakthavatchalu V, Matthews C, Dawson D, Steffen M, et al. Rat Model of Polymicrobial Infection, Immunity, and Alveolar Bone Resorption in Periodontal Disease. Infect Immun, 2007;75:1704-1712.

Khurshid Z, Zafar M, Qasim S, Shahab S, Naseem M, AbuReqaiba A. Advances in Nanotechnology for Restorative Dentistry. Materials, 2015;8:717-731.

Kohli P, Martin CR. Smart nanotubes for biomedical and biotechnological applications. Drug News Perspect, 2003;16:566-573.

Kong LX, Peng Z, Li SD, Bartold PM. Nanotechnology and its role in the management of periodontal diseases. Periodontol 2000, 2006;40:184-196.

Kornman KS. Controlled-release local delivery antimicrobials in periodontics: prospects for the future. J Periodontol, 1993;64:782-791.

Lee SY, Kwon HK, Kim BI. Effect of dentinal tubule occlusion by dentifrice containing nano-carbonate apatite. J Oral Rehabil, 2008;35:847-853.

Lei C, Jiyao L, Hockin X, Xuedong Z. 2016. Demineralization and Remineralization. In: Xuedong Z, ed. Dental Caries: Principle and Management. Berlin: Springer Berlin Heidelberg, 71-84.

Lorden ER, Levinson HM, Leong KW. Integration of drug, protein, and gene delivery systems with regenerative medicine. Drug Deliv Transl Res, 2015;5:168-186.

Melo MAS, Guedes SFF, Xu HHK, Rodrigues LKA. Nanotechnology-based restorative materials for dental caries management. Trends Biotechnol, 2013;31:459-467.

Mieszawska AJ, Mulder WJM, Fayad ZA, Cormode DP. Multifunctional Gold Nanoparticles for Diagnosis and Therapy of Disease Mol Pharm, 2013;10:831-847.

Nakashima S, Yoshie M, Sano H, Bahar A. Effect of a test dentifrice containing nano-sized calcium carbonate on remineralization of enamel lesions in vitro. J Oral Sci, 2009;51:69-77.

Osorio R, Alfonso-Rodríguez CA, Medina-Castillo AL, Alaminos M, Toledano M. Bioactive Polymeric Nanoparticles for Periodontal Therapy. PLoS One, 2016;11:e0166217.

Ozak ST, Ozkan P. Nanotechnology and dentistry. Eur J Dent, 2013;7:145-151.

Petersen PE, Ogawa H. The global burden of periodontal disease: Towards integration with chronic disease prevention and control. Periodontol 2000, 2012;60:15-39.

Pihlstrom BL, Michalowicz BS, Johnson NW. Periodontal diseases. Lancet, 2005;366:1809-1820. 
Piñón-Segundo E, Ganem-Quintanar A, Alonso-Pérez V, Quintanar-Guerrero D. Preparation and characterization of triclosan nanoparticles for periodontal treatment. Int J Pharm, 2005;294:217-232.

Pragati S, Ashok S, Kuldeep S. Recent advances in periodontal drug delivery systems. Int J Drug Deliv, 2009;1:1-14.

Pramod K, Aminu N, Ali J. 2014. Targeted Drug Delivery Systems for the Treatment of Periodontal Infections. In: Singh B, Katare OP, Govil JN, eds. Biotechnology Vol. 8, Novel Drug Delivery. U.S.A.: Studium Press LLC, 97-128.

Puri K, Puri N. Local drug delivery agents as adjuncts to endodontic and periodontal therapy. J Med Life, 2013;6:414-419.

Rahiotis C, Vougiouklakis G, Eliades G. Characterization of oral films formed in the presence of a $\mathrm{CPP}-\mathrm{ACP}$ agent: An in situ study. $\mathrm{J}$ Dent, 2008;36:272-280.

Sahoo SK, Parveen S, Panda JJ. The present and future of nanotechnology in human health care. Nanomedicine, 2007;3:20-31.

Samuel SP, Li S, Mukherjee I, Guo Y, Patel AC, Baran G, et al. Mechanical properties of experimental dental composites containing a combination of mesoporous and nonporous spherical silica as fillers. Dent Mater, 2009;25:296-301.

Saxl T. 2011. The mechanics of nanomedicine. [ONLINE] Available at: http://www.historyofnimr.org.uk/mill-hill-essays/essaysyearly-volumes/20112012-2/the-mechanics-of-nanomedicine/ [Accessed 11 November 2016].

Schwach-Abdellaoui K, Vivien-Castioni N, Gurny R. Local delivery of antimicrobial agents for the treatment of periodontal diseases. Eur J Pharm Biopharm, 2000;50:83-99.

Simch RP, Gaio EJ, Rosing CK. Effect of body weight in the pathogenesis of ligature-induced periodontal disease in Wistar rats. Acta Odontol Scand, 2008;66:130-134.

Suzuki O. Biological Role of Synthetic Octacalcium Phosphate in Bone Formation and Mineralization. J Oral Biosci, 2010;52:6-14.

Tanner ACR. Anaerobic culture to detect periodontal and caries pathogens. J Oral Biosci, 2015;57:18-26.

U.S. National Cancer Institute. 2016. Cantilevers. Nanoscale Cantilevers. [ONLINE] Available

at: http://nano.cancer.gov/learn/understanding/nanotech_cantilevers.asp [Accessed 11 November 2016].

Vandiver J, Dean D, Patel N, Bonfield W, Ortiz C. Nanoscale variation in surface charge of synthetic hydroxyapatite detected by chemically and spatially specific high-resolution force spectroscopy. Biomaterials, 2005;26:271-283.
Vinhas R, Cordeiro M, Carlos FF, Mendo S, Fernandes AR, Figueiredo $\mathrm{S}$, et al. Gold nanoparticle-based theranostics: disease diagnostics and treatment using a single nanomaterial. Nanobiosensors Dis Diagnosis, 2015;4:11-23.

Walmsley GG, McArdle A, Tevlin R, Momeni A, Atashroo D, Hu MS, et al. Nanotechnology in bone tissue engineering. Nanomedicine, 2015;11:1253-1263.

Wang L, Xie X, Imazato S, Weir MD, Reynolds MA, Xu HHK. A protein-repellent and antibacterial nanocomposite for Class-V restorations to inhibit periodontitis-related pathogens. Mater Sci Eng C, 2016;67:702-710.

Wang Y, Zheng D, Tan Q, Wang MX, Gu L-Q. Nanoporebased detection of circulating microRNAs in lung cancer patients. Nat Nanotechnol, 2011;6:668-674.

West JL, Halas NJ. Engineered Nanomaterials for Biophotonics Applications: Improving Sensing, Imaging, and Therapeutics. Annu Rev Biomed Eng, 2003;5:285-292.

Yao W, Xu P, Pang Z, Zhao J, Chai Z, Li X, et al. Local delivery of minocycline-loaded PEG-PLA nanoparticles for the enhanced treatment of periodontitis in dogs. Int $\mathbf{J}$ Nanomedicine, 2014;9:39633970 .

Zamani M, Morshed M, Varshosaz J, Jannesari M. Controlled release of metronidazole benzoate from poly epsilon-caprolactone electrospun nanofibers for periodontal diseases. Eur J Pharm Biopharm, 2010;75:179-185.

Zupančič Š, Baumgartner S, Lavrič Z, Petelin M, Kristl J. Local delivery of resveratrol using polycaprolactone nanofibers for treatment of periodontal disease. J Drug Deliv Sci Technol, 2015a;30:408-416.

Zupancic S, Kocbek P, Baumgartner S, Kristl J. Contribution of Nanotechnology to Improved Treatment of Periodontal Disease. Curr Pharm Des, 2015b; 21: 3257-3271.

How to cite this article:

Aminu N, Chan SY, Toh SM. Roles of Nanotechnological Approaches in Periodontal Disease Therapy. J App Pharm Sci, 2017; 7 (07): 234-242. 